\title{
Religious attendance after elevated depressive symptoms: is selection bias at work?
}

\begin{abstract}
In an attempt to determine if selection bias could be a reason that religious attendance and depression are related, the predictive value of elevated depressive symptoms for a decrease in future attendance at religious services was examined in a longitudinal panel of 1,673 Dutch adults. Religious attendance was assessed yearly over five years using the single question, "how often do you attend religious gatherings nowadays?" Depressive symptoms were assessed four times within the first year using the Depression subscale of the Brief Symptom Inventory. Logistic regression models of change in attendance were created, stratifying by baseline attendance status. Attenders who developed elevated symptoms were less likely to subsequently decrease their attendance (relative risk ratio: $0.55,95 \% \mathrm{Cl}: 0.38$ to 0.79 ) relative to baseline as compared to those without elevated symptoms. This inverse association remained significant after controlling for health and demographic covariates, and when using multiply imputed data to account for attrition. Nonattenders were unlikely to start attending after elevated depressive symptoms. This study provides counter evidence against previous findings that church attenders are a self-selected healthier group.
\end{abstract}


$3 *$ Department of Psychiatry

4 University of Saskatchewan

5 Saskatoon, Saskatchewan

6 CANADA S7H 3W6

\section{Introduction:}


Attendance at religious services is usually reported to be inversely related to depression

9 (Baetz et al. 2004; Balbuena et al. 2013; Hayward et al. 2012; Maselko et al. 2009). However, as

10 with many findings in the literature on religion and depression, the results have not been

11 consistent, with other studies reporting a null (Ellison \& Flannelly 2009; Miller et al. 2012;

12 Schnittker 2001) or curvilinear relationship of attendance and depression (Taylor et al. 2012).

13 This inconsistency has been due in part to the predominance of cross-sectional designs, which

14 cannot establish causation. We are aware of only three longitudinal studies examining the

15 relation of depression to subsequent religious attendance. Recently, it was reported (Maselko et

16 al. 2012) that women having an onset of depression prior to age 18 were more likely to stop

17 attending religious services as adults compared to those with adult-onset MDE and those with no

18 lifetime MDE. Similarly, a longitudinal study (Horowitz \& Garber 2003) reported that

19 depressive episodes in grades 7-11 predicted lower levels of religious attendance in grade 12.

20 The latter result is ambiguous because religious attendance in grade 6 also predicted lower odds

21 of depression in grades 7-12, although the effect was just shy of statistical significance. Miller

22 and colleagues (2002) followed a cohort of 146 individuals who had an MDE in childhood

23 together with a control group of 123 who had no psychiatric disorder over 11 years. At follow-

24 up, the rates of religious attendance between groups did not differ by childhood depression status.

25 It is noteworthy that these studies covered the adolescence-to-adult transition period. Late

26 adolescence is generally a time of profound change. The quest to establish one's identity and

27 career (Arnett 2000) and experimentation with cohabitation, drugs, and alcohol (Benda \&

28 Corwyn 1997; Thornton et al. 1992; Uecker et al. 2007) could precipitate internal conflicts with

29 religious doctrine, leading to declines in religious attendance. In short, the developmental

30 processes occurring during adolescence confounds the relation of depression with religious

31 attendance, in either causal direction. 
33 subsequent religious attendance. First, depressed individuals may withdraw from public worship

34 as part of the overall social disengagement that occurs in depression (Maselko et al. 2012).

35 Secondly, churchgoers might be less susceptible to depression. A meta-analysis of 94 studies

36 reported a positive correlation of agreeableness, conscientiousness, and sociability with religious

37 social investment (Lodi-Smith \& Roberts 2007). In summary, theory suggests that depressed

38 individuals select themselves out of the churchgoing demographic while healthy ones select

39 themselves into it. These selection effects, if operative, would likely overestimate the protective

40 value of religion for mental health.

41 The protective value of religiosity does have empirical support. Coping with adversity

42 through religion is well-documented in the literature (Pargament 1997). "Turning to God or

43 religion" as a coping strategy has been reported in cancer patients (Bussing et al. 2007), newly

44 bereaved individuals (Brown et al. 2004), and new immigrants (Connor 2009). A study

45 comparing religiosity and spirituality before and after HIV patients were informed of the

46 diagnosis (Ironson et al. 2006) reported that religiosity (including attendance) increased after the

47 diagnosis became known. Furthermore, increased religiosity was associated with greater CD4

48 helper cells in the blood, indicating slower HIV progression (Ironson et al. 2006). A US

49 longitudinal study reported that depressed individuals were more likely to seek religious

50 consolation - defined as searching for meaning in problems and difficulties(Ferraro \& Kelley-

51 Moore 2000). Importantly, even those with no initial religious affiliation sought religious

52 consolation after depression. This finding seems to support the "no atheists in foxholes"

53 aphorism. However, adversity or trauma can also cause individuals to turn away from God or

54 religion (Chen \& Koenig 2006; Fontana \& Rosenheck 2004). We are not aware of longitudinal

55 studies reporting changes to religious attendance per se (vis-a-vis religiosity broadly speaking) 
56 after a depressive episode aside from the three studies in adolescence (Horowitz \& Garber 2003;

57 Maselko et al. 2012; Miller et al. 2002) already mentioned.

58 In this paper, our main objective was to study whether elevated depressive symptoms

59 introduce selection bias in a longitudinal follow-up of religious attendance. Our research

60 questions were as follows. First, do religious attenders who develop elevated depressive

61 symptoms subsequently decrease their attendance level? Second, do non-attenders who develop

62 elevated symptoms begin to attend services?

63 Materials and Methods

64 Sample

65 The data is from the Longitudinal Internet Studies for the Social Sciences (LISS) panel, a

66 random sample of adults living in the Netherlands (Scherpenzeel 2011). The panel of almost

678,000 individuals was drawn from the Dutch-speaking population based on a list of addresses

68 provided by Statistics Netherlands. The recruitment strategy is described in more detail

69 elsewhere (Scherpenzeel 2011). LISS is a continuing study in which participants complete online

70 questionnaires monthly on topics including family, economic situation, health, and religion. Each

71 LISS participant has a unique member ID, so it is possible to combine their responses across

72 different survey modules and from one wave to another. For the purpose of our study, we merged

73 the religion $(\mathrm{n}=7,418)$ and mental health $(\mathrm{n}=1,804)$ modules, narrowing our sample to those

74 who responded to both surveys $(\mathrm{n}=1,718)$. Waves of religion and depression assessments were

75 not simultaneous, so hereafter, use the notation $R_{i}$ and $D_{i}$ to refer to religion and depression

76 waves, respectively. Our research question requires the following temporal sequence: $R_{1} \rightarrow D_{2}$ to

$77 \quad D_{4} \rightarrow R_{2}$. By comparing attendance level at $R_{2}$ with $R_{1}$, we can test whether depression predicts a

78 relative decrease at $R_{2}$. This design requirement forced us to exclude those individuals $(n=41)$

79 who had a different sequence of assessments: 
$\mathrm{D}_{1} \rightarrow \mathrm{D}_{2} \rightarrow \mathrm{R}_{1} \rightarrow \mathrm{D}_{2}$ to $\mathrm{D}_{4}$, since for these individuals, one cannot compare attendance levels

81 before and after depression. Our effective sample size was 1,673.

$82 \quad$ (Insert Figure 1 around here)

83 In the sample, 887 individuals did not attend services and 786 attended services at $\mathrm{R}_{1}$.

84 (Explained in Measures section below.) The characteristics of these groups are described in Table

85 1. After baseline assessment, $D_{1}$, depression was assessed during a seven-month span from

86 March to September 2008 while attendance was assessed another four times in addition to R1,

87 and these assessments occurred on each January from 2009 to 2012 . Our main analytic strategy

88 was to compare the proportion of individuals that changed their attendance level, stratified by

89 baseline attendance. The change in attendance level was indexed to $R_{1}$ attendance since there

90 were no further depression assessments after September 2008.

$91 \quad$ (Insert Table 1 around here)

92 Measures

Religious attendance was assessed with the single question, "Aside from special

94 occasions such as weddings and funerals, how often do you attend religious gatherings

95 nowadays?" This was answered on a 7-point Likert scale coded as $1=$ everyday, $2=$ more than

96 once a week, $3=$ once $a$ week, $4=$ at least once a month, $5=$ only on special religious days, $6=$

97 less often, and $7=$ never. We reverse coded the scale for ease of interpretation-i.e., larger

98 number indicated higher attendance. Among attenders, we used a dichotomous attendance

99 variable for decreased (coded 0 ) and same/increased (coded 1) and a categorical version:

100 decreased, unchanged, and increased attendance. These categories were formed by subtracting

101 the $\mathrm{R}_{1}$ attendance level from a given follow-up assessment. For non-attenders in $\mathrm{R}_{1}$, a

102 dichotomous variable with unchanged (coded 0) and increased (coded 1) was used.

103 Our substantive predictor was assessed using the Depression subscale of the Brief

104 Symptom Inventory (Derogatis 1975). The subscale consists of 6 items rated on a 5-point scale 
105 from "Not at all" to "Extremely". The BSI is itself a short version of the SCL-90 (Derogatis \&

106 Melisaratos 1983). BSI Depression had an internal reliability ranging from 0.70 to 0.92 in four

107 different studies (Boulet \& Boss 1991; Derogatis \& Melisaratos 1983; Johnson et al. 2008;

108 Kellett et al. 2003) and correlated with the Beck Depression Inventory, $r=.71$ and $r=.77$, in two

109 other studies (Stukenberg et al. 1990; Prinz et al. 2013). Two studies validated BSI Depression

110 against either DSM-III or DSM-IV-TR major depression (Stukenberg et al. 1990; Johnson et al.

111 2008). ROC analyses reported area under the curve as 0.83 in community dwelling older adults,

112 but a more modest 0.65 among psychiatric inpatients.

113 For copyright reasons, the LISS dataset only provided the normative category of each

114 respondent and not the responses to individual questions. These normative categories of BSI

115 depression were: 1 = very low, $2=$ low, 3 =below average, $4=$ average, and $5=$ above

116 average, $6=$ high, $7=$ very high. We dichotomized them into low (very low to above average)

117 and elevated (high to very high). The cut-off was chosen because it resulted in a better

118 approximation of the prevalence of depression in the Netherlands (Bijl et al. 1998) compared to

119 alternative cut-offs.

120 Covariates

121 We controlled for possible confounders including chronic health conditions, income,

122 marital status, age, and gender. Chronic conditions were assessed with the single question, " $D o$

123 you suffer from any kind of long-standing disease, affliction or handicap, or do you suffer from

124 the consequences of an accident?" Income was assessed using a monthly personal gross income

125 with five categories: 0-500, 501-1500, 1501-2500, 2501-3500, and 3501 and higher Euros per

126 month. Marital status was used as an index of social support and was categorized into $1=$ 
127 Married; 2=Separated/Divorced/Widowed; 3= Not Married. All covariates were measured

128 between December 2007 and January 2008.

129 Statistical analysis

130 We first compared demographic characteristics of attenders and non-attenders at baseline.

131 To examine whether elevated depressive symptoms predicted subsequent decreased attendance,

132 we crosstabulated dichotomized attendance with level of symptoms among attenders, for each

133 religion follow-up year. Chi-square tests of association were performed. To examine change

134 longitudinally and control for confounders, we created a multinomial logistic regression model

135 among attenders. Relative risk ratios of decreasing or increasing attendance over maintaining

136 attendance were calculated.

137 To examine if non-attenders start attending services after elevated depression, a binary

138 logistic regression model was created with change in attendance $(0=$ no change; $1=$ attended $)$ as

139 dependent variable. We entered the covariates in all regression models to control for confounding

140 and robust standard errors were calculated to account for correlated errors in repeated

141 observations.

142 Missing data

143 Missing values for the covariates at baseline did not differ between attenders and non-

144 attenders. To examine whether our results would be biased by differential attrition between

145 attenders and non-attenders, we performed multiple imputation on our dependent and predictor

146 variables using a set of 15 socio-demographic and psychological variables assessed at baseline.

147 (These variables are available from the authors upon request.) The imputation procedure was

148 implemented using REALCOM-IMPUTE (Carpenter et al. 2011) software and 10 imputed 
149 datasets were generated, which were then analyzed using Stata 12.1. Our regression models were 150 then repeated using the multiply imputed data.

\section{Results:}

152 Religious attenders were more likely to be female, older, and married as compared to non153 attenders. Attenders and non-attenders were similar in self-rated health, in the proportion having 154 chronic conditions, and in the distribution of BSI Depression normative scores. From March to 155 September 2008, 491 individuals developed elevated depression. The chi-square tests in each of

156 the four follow-up waves showed no association between depression status and subsequent

157 decrease in attendance with one exception. In 2012, those with elevated BSI Depression among

158 baseline attenders were more likely to keep or increase their 2008 attendance levels. In post-hoc

159 analysis, we repeated the change in attendance analysis by depression category stratified first by 160 gender and then by age category. In gender-stratified analysis, no associations were found in 161 each attendance follow-up. In age-stratified analysis, no associations were found in the first two 162 years after depression assessments took place. In both $\mathrm{R}_{3}$ and $\mathrm{R}_{4}$, those 48 years old and above 163 and with elevated depression were more likely to maintain or increase attendance levels (both

$164 \mathrm{p}$ 's $<.05$ ). (See Table 2. The tables stratified by gender or age category are available from the 165 authors by request.)

$166 \quad$ (Insert Table 2 around here)

167 In multinomial logistic regression modeling, elevated symptoms predicted lower

168 probability of a decrease in attendance (Relative Risk Ratio $=0.55 ; 95 \%$ CI: 0.38 to 0.79 )

169 relative to baseline attendance levels among attenders. Among non-attenders, elevated symptoms

170 were unrelated to a subsequent increase in attendance with one exception. The estimates were not

171 materially different when the models were run using multiply imputed data.

172 (Insert Table 3 and Figure 2 here.) 
Discussion:

The main finding in this study is that elevated BSI depression does not cause a subsequent

175 decrease in attendance. On the contrary, elevated BSI depression predicts same or increased

176 levels of attendance as compared with prior to elevated BSI depression. None of our results

177 across three analytical strategies showed a decrease in attendance. Although unstratified analyses

178 did not yield a significant association, gender and age-stratified results indicated an association of

179 continued or increased attendance with elevated symptoms. We do not interpret this association

180 because other variables could possibly explain the association. The multinomial logistic model

181 among attenders, with covariates controlled for, indicated that elevated symptoms predicted same

182 or increased attendance. As a secondary finding, non-attenders were not likely to seek recourse

183 in religion by starting to attend services.

184 Our main finding addresses the issue of selection bias in studies of religious attendance

185 and mental health. To recap, when depressed individuals stop attending services, the apparent

186 protection afforded by attendance would be inflated. This selection bias would be most

187 pronounced in cross-sectional studies. In longitudinal epidemiologic studies, bias remains an

188 issue because there might be differential attrition in attendance by depression status. Since we

189 found that attenders who develop elevated symptoms become less likely to drop out of worship,

190 then they might in effect be overrepresented among churchgoers. Therefore, the protective effect

191 of religious attendance might in fact be underestimated, contrary to the reverse causation

192 argument.

193 Religious individuals turn to their faith in times of distress as a means of coping (Brown

194 et al. 2004; Bussing et al. 2007; Ironson et al. 2006). Religious worship is a source of social

195 support and allows individuals to cope with life-threatening conditions by providing "medicine

196 for the spirit.” (Cummings \& Pargament 2010) A longitudinal study (Li \& Ferraro 2005) on

197 depression and volunteering among older adults reported that elevated depression at wave 2 
predicted seeking out volunteering opportunities at wave 3 . This was explained as a

199 compensatory mechanism to alleviate negative affect, via social integration. These older adults

200 had physical health problems in addition to depression and the physical health problems were the

201 operative barriers. Consistent with this finding, Chen and Koenig (2006) reported that in elderly,

202 medically ill individuals, an increased severity of physical illness predicted a decrease in

203 organizational religiousness. Importantly, the association was completely mediated by physical

204 activity limitations. Together with our own results, these suggest that it is not depression per se

205 that causes a disengagement from participation in religious service. In effect, reverse causation

206 and non-random attrition might be more relevant to studies examining religious attendance and

207 physical health.

The null association of elevated depression with subsequent attendance among non-

209 attenders indicates that non-attenders do not start attending in the face of adversity. By contrast,

210 Ferraro and Kelley-Moore (2000) reported that depression, cancer, and chronic conditions lead to

211 consolation-seeking even among those with no religious affiliation. The two points of view can

212 be reconciled because attendance is not necessary for consolation-seeking. The need to find

213 meaning in illness is shared by believers and non-believers who may turn to nature, arts, music,

214 and relationships (Burnard 1988).

215 An intriguing study (Farias et al. 2013) reported that rowers about to enter a competition

216 reported greater belief in science as compared with those in a training session. The authors

217 concluded that affirming one's secular worldview serves a similar function as religious faith in

218 moments of stress or existential anxiety. Hence, affiliated individuals cope by means of religion

219 while non-attending ones seek support and meaning elsewhere. It appears that depressive

220 symptoms are not a strong driver of entry into or exit from the churchgoing demographic. More

221 empirical research is needed to validate this interpretation. 
223 the BSI to assess depressive symptoms. It has been argued that although the global BSI scale is a 224 valid measure of distress, it is not intended to screen for particular psychiatric disorders (Asner-

225 Self et al. 2006). We set the BSI cut-off for depression at "high" or "very high" but there is no 226 way to tell whether this is in concordance with clinically diagnosed depression. We therefore 227 allow for the possibility that the depressed group that we studied might differ from a group with 228 formally diagnosed major depression (Sareen et al. 2013). Secondly, there were no assessments 229 of depression from 2009 to 2012 - the period during which religious attendance was compared to 230 initial attendance. As such, all religious attendance changes were indexed to depression levels in 2312008 only. We cannot rule out the possibility that attendance levels after 2008 were related to 232 unmeasured elevated symptoms after 2008. Third, the sample that we worked with was restricted 233 to LISS participants who responded to both religion and mental health modules and might not be 234 representative of the Dutch national population. Fourth, while we have ruled out sampling bias in 235 terms of attrition in attendance, we could not address whether personality traits such as greater 236 resilience to depression characterized attenders in the first place. Finally, other health-related 237 reasons, including physical disability, might be correlated with depression and could cause 238 selection bias. This is beyond the scope of our study. The major strength of this study was that 239 depression assessments were proximal to those of religion. Our sample also consisted of a small 240 fraction $(5 \%)$ of late adolescents and is less affected by the well-reported decline in religious 241 attendance in adolescence.

242 Within the limitations of our study, we conclude that elevated depressive symptoms do 243 not cause religiously affiliated individuals to subsequently decrease attendance at religious 244 services.

245 Acknowledgments: The authors are grateful to the CentERdata at Tilburg University in the 246 Netherlands for making the data available for use. 
Conflicts of Interest: none

\section{References:}

249 Arnett JJ. 2000. Emerging adulthood - A theory of development from the late teens through the $250 \quad$ twenties. American Psychologist 55:469-480.

251 Asner-Self KK, Schreiber JB, and Marotta SA. 2006. A cross-cultural analysis of the Brief 252 Symptom Inventory-18. Cultur Divers Ethnic Minor Psychol 12:367-375.

253 Baetz M, Griffin R, Bowen R, Koenig HG, and Marcoux E. 2004. The association between 254 spiritual and religious involvement and depressive symptoms in a Canadian population. $J$ $255 \quad$ Nerv Ment Dis 192:818-822.

256 Balbuena L, Baetz M, and Bowen R. 2013. Religious attendance, spirituality, and major 257 depression in Canada: a 14-year follow-up study. Can J Psychiatry 58:225-232.

Benda BB, and Corwyn RF. 1997. A test of a model with reciprocal effects between religiosity 259 and various forms of delinquency using 2-stage least squares regression. Journal of Social Service Research 22:27-52.

Bijl RV, Ravelli A, and van Zessen G. 1998. Prevalence of psychiatric disorder in the general

Brown SL, Nesse RM, House JS, and Utz RL. 2004. Religion and emotional compensation: population: results of the Netherlands Mental Health Survey and Incidence Study (NEMESIS). Soc Psychiatry Psychiatr Epidemiol 33:587-595.

Boulet J, and Boss M. 1991. Reliability and Validity of the Brief Symptom Inventory. Results from a prospective study of widowhood. Personality and Social Psychology Bulletin 30:1165-1174.

Burnard P. 1988. The spiritual needs of atheists and agnostics. Prof Nurse 4:130-132. 
270

271

272

273

274

275

276

277

278

279

280

281

282

283

284

285

286

287

288

289

290

291

292

293

294

Bussing A, Ostermann T, and Koenig HG. 2007. Relevance of religion and spirituality in German patients with chronic diseases. Int J Psychiatry Med 37:39-57.

Carpenter JR, Goldstein H, and Kenward MG. 2011. REALCOM-IMPUTE Software for Multilevel Multiple Imputation with Mixed Response Types. Journal of Statistical Software 45:1-14.

Chen YY, and Koenig HG. 2006. Do people turn to religion in times of stress?: an examination of change in religiousness among elderly, medically ill patients. J Nerv Ment Dis 194:114120.

Connor P. 2009. Immigrant Religiosity in Canada: Multiple Trajectories. International Migration \& Integration 10:159-175.

Cummings JP, and Pargament KI. 2010. Medicine for the Spirit: Religious Coping in Individuals with Medical Conditions. Religions 1:28-53.

Derogatis LR. 1975. Brief Symptom Inventory. Baltimore: Clinical Psychometric Research.

Derogatis LR, and Melisaratos N. 1983. The Brief Symptom Inventory - an Introductory Report. Psychological Medicine 13:595-605.

Ellison CG, and Flannelly KJ. 2009. Religious involvement and risk of major depression in a prospective nationwide study of African American adults. J Nerv Ment Dis 197:568-573.

Farias M, Newheiser A-K, Kahane G, and de Toledo Z. 2013. Scientific fiath: Belief in science increases in the face of stress and existential anxiety. Journal of Experimental Social Psychology.

Ferraro KF, and Kelley-Moore JA. 2000. Religious consolation among men and women: Do health problems spur seeking? Journal for the Scientific Study of Religion 39:220-234.

Fontana A, and Rosenheck R. 2004. Trauma, change in strength of religious faith, and mental health service use among veterans treated for PTSD. J Nerv Ment Dis 192:579-584.

Hayward RD, Owen AD, Koenig HG, Steffens DC, and Payne ME. 2012. Religion and the presence and severity of depression in older adults. Am J Geriatr Psychiatry 20:188-192. 
295

296

297

298

299

300

301

302

303

304

305

306

307

308

309

310

311

312

313

314

315

316

317

318

319

320

321

Horowitz JL, and Garber J. 2003. Relation of intelligence and religiosity to depressive disorders in offspring of depressed and nondepressed mothers. J Am Acad Child Adolesc Psychiatry 42:578-586.

Ironson G, Stuetzle R, and Fletcher MA. 2006. An increase in religiousness/spirituality occurs after HIV diagnosis and predicts slower disease progression over 4 years in people with HIV. J Gen Intern Med 21 Suppl 5:S62-68.

Johnson ME, Chipp CL, Brems C, and Neal DB. 2008. Receiver operating characteristics for the brief symptom inventory depression, paranoid ideation, and psychoticism scales in a large sample of clinical inpatients. Psychol Rep 102:695-705.

Kellett S, Beail N, Newman DW, and Frankish P. 2003. Utility of the brief symptom inventory in the assessment of psychological distress. Journal of Applied Research in Intellectual Disabilities 16:127-134.

Li YQ, and Ferraro KF. 2005. Volunteering and depression in later life: Social benefit or selection processes? Journal of Health and Social Behavior 46:68-84.

Lodi-Smith J, and Roberts BW. 2007. Social investment and personality: A meta-analysis of the relationship of personality traits to investment in work, family, religion, and volunteerism. Personality and Social Psychology Review 11:68-86.

Maselko J, Gilman SE, and Buka S. 2009. Religious service attendance and spiritual well-being are differentially associated with risk of major depression. Psychological Medicine 39:1009-1017.

Maselko J, Hayward RD, Hanlon A, Buka S, and Meador K. 2012. Religious service attendance and major depression: a case of reverse causality? Am J Epidemiol 175:576-583.

Miller L, Weissman M, Gur M, and Greenwald S. 2002. Adult religiousness and history of childhood depression: eleven-year follow-up study. J Nerv Ment Dis 190:86-93.

Miller L, Wickramaratne P, Gameroff MJ, Sage M, Tenke CE, and Weissman MM. 2012. Religiosity and major depression in adults at high risk: a ten-year prospective study. Am J Psychiatry 169:89-94. 
322

323

324

325

326

327

328

329

330

331

332

333

334

335

336

337

338

339

340

341

342

343

344

Pargament KI. 1997. The psychology of religion and coping : theory, research, practice. New York ; London: Guilford Press.

Prinz U, Nutzinger DO, Schulz H, Petermann F, Braukhaus C, and Andreas S. 2013.

Comparative psychometric analyses of the SCL-90-R and its short versions in patients with affective disorders. BMC Psychiatry 13:104.

Sareen J, Henriksen CA, Stein MB, Afifi TO, Lix LM, and Enns MW. 2013. Common mental disorder diagnosis and need for treatment are not the same: findings from a populationbased longitudinal survey. Psychological Medicine 43:1941-1951.

Scherpenzeel A. 2011. Data Collection in a Probability-Based Internet Panel: How the LISS Panel Was Built and How It Can be Used. Bulletin of Sociological Methodology: Association Internationale de Methodologie Sociologique. p 56-61.

Schnittker J. 2001. When is Faith Enough? The Effects of Religious Involvement on Depression. Journal for the Scientific Study of Religion 40:393-411.

Stukenberg KW, Dura JR, and Kiecolt-Glaser JK. 1990. Depression Screening Scale Validation in an Elderly, Community-Dwelling Population. Psychological Assessment: A Journal of Consulting \& Clinical Psychology 2:134-138.

Taylor RJ, Chatters LM, and Nguyen AW. 2012. Religious Participation and DSM IV Major Depressive Disorder Among Black Caribbeans in the United States. J Immigr Minor Health.

Thornton A, Axinn WG, and Hill DH. 1992. Reciprocal Effects of Religiosity, Cohabitation, and Marriage. American Journal of Sociology 98:628-651.

Uecker JE, Regnerus MD, and Vaaler ML. 2007. Losing my religion: The social sources of religious decline in early adulthood. Social Forces 85:1667-1692. 


\section{Table 1 (on next page)}

Comparison of Attenders and Non-attenders

Figures in this table are $n(\%)$ except for age and self-rated health which are mean (sd). ${ }^{*}$ Rated on a scale of 1 to 5 , with higher scores indicating better health. 
Table 1: Characteristics of Dutch individuals who responded to Mental Health (Wave 1) and Religious Attendance (Wave 1--Jan 2008) of the Longitudinal Internet Studies for the Social Sciences (LISS), Netherlands $(\mathrm{n}=1,673)$

\section{Service Attenders at R1}

$\mathrm{n}$

Mean age (sd)

Civil status

Unmarried

Married

Monthly income

Low income (0 to $500 €$ per

month)

Not low income ( $>500 €$ per

month)

Mean self-rated health (sd)*

With a chronic condition

$49.60(18.22)$
$323(41)$

463(59)

$77(10)$

$709(90)$

$3.12(0.76)$

$232(32)$

$497(68)$
Non-attenders of

Service at R1

887

$45.90(17.21)<.001$

$443(50)<.001$

$444(50)$

difference

$(50)$

$65(7) \quad .07$

822 (93)

$3.13(0.76) \quad .68$

227 (27)

$600(73) \quad .06$

Baseline distribution of BSI

depression normative scores

Very low

$0(0)$

$0(0)$

Low

$0(0)$

Below average

$113(14)$

$0(0)$

145 (16)

Average

$196(25)$

Above average

284 (36)

High

$168(21)$

Very high

25 (3)

.38

324 (37)

$162(18)$

$22(2)$

Note: Figures in this table are n (\%) except for age and self-rated health which are mean (sd).

*Rated on a scale of 1 to 5, with higher scores indicating better health. 


\section{Figure 1}

\section{Subjects}

\section{(A) LISS datasets used and participant flowchart; (B) Schedule of religion and depression}

assessments

A.

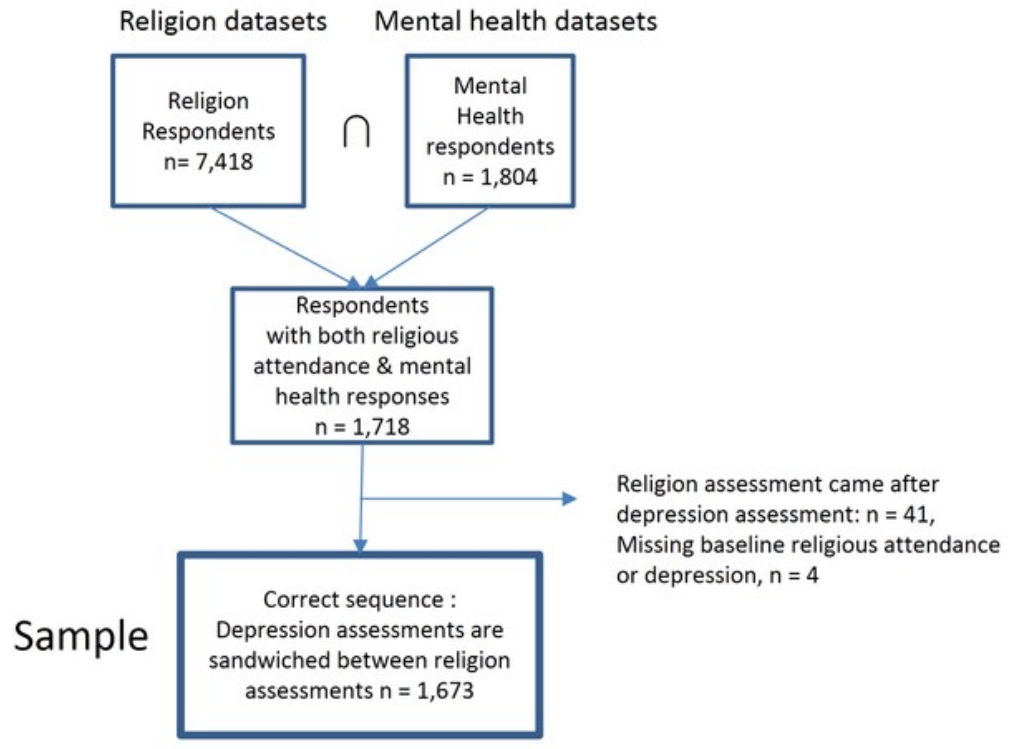

B.

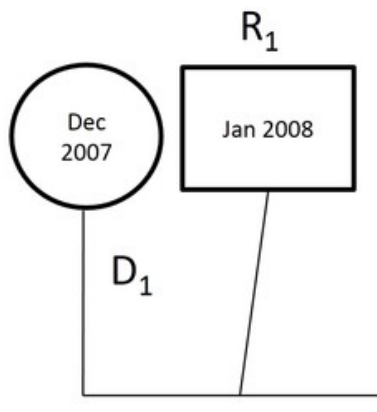

A. Baseline assessment

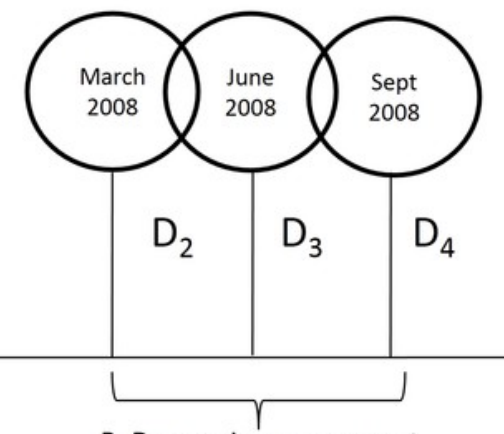

B. Depression assessment
$\begin{array}{llll}\mathrm{R}_{2} & \mathrm{R}_{3} & \mathrm{R}_{4} & \mathrm{R}_{5}\end{array}$

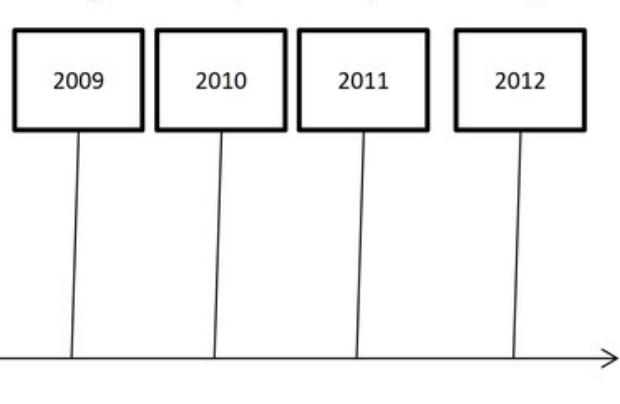

C. Attendance follow-up 


\section{Table 2 (on next page)}

Change in Attendance by Depression Status

If the individual had a norm-referenced score of "high" or "very high" in any of the three assessments in 2008, the individual was assigned to elevated and otherwise to unelevated. Abbreviation: $\mathrm{BSI}=$ Brief Symptom Inventory 
Table 2: Elevated BSI Depression vs Changes in Attendance in the Longitudinal Internet Studies for the Social Sciences (LISS), Netherlands

Service Attenders at R1

\begin{tabular}{|c|c|c|c|c|c|c|c|c|c|}
\hline \multirow[t]{4}{*}{2009} & Unelevate & Elevated & $\chi^{2}$ & $\mathrm{p}$ & \multirow{4}{*}{$\begin{array}{l}2009 \\
\text { Attendan } \\
\text { ce } \\
\text { vs } 2008\end{array}$} & Unelevate & Elevated & \multirow[t]{4}{*}{$\chi^{2}$} & \multirow[t]{4}{*}{$n$} \\
\hline & Depressio & Depressio & & & & Depressio & Depressio & & \\
\hline & $\mathrm{n}$ & $\mathrm{n}$ & & & & $\mathrm{n}$ & $\mathrm{n}$ & & \\
\hline & $\mathrm{n}(\%)$ & $\mathrm{n}(\%)$ & & & & $\mathrm{n}(\%)$ & $\mathrm{n}(\%)$ & & \\
\hline $\begin{array}{l}\text { Same or } \\
\text { increase }\end{array}$ & $371(73)$ & $184(78)$ & $\begin{array}{r}2.3 \\
1\end{array}$ & 13 & Same & $394(67)$ & $177(69)$ & \multirow[t]{2}{*}{.47} & \\
\hline ise & $139(27)$ & $52(22)$ & & & Increase & $194(33)$ & $78(31)$ & & \\
\hline
\end{tabular}

\section{Non-attenders of Service at R1}

Unelevate Elevated $\chi^{2} \quad \mathrm{p}$

\begin{tabular}{|c|c|c|c|c|c|c|c|c|c|}
\hline \multirow{4}{*}{$\begin{array}{l}2010 \\
\text { Attendan } \\
\text { ce } \\
\text { vs } 2008\end{array}$} & Unelevate & Elevated & $\chi^{2}$ & $\mathrm{p}$ & 2010 & Unelevate & Elevated & \multirow[t]{4}{*}{$\chi^{2}$} & \multirow[t]{4}{*}{$\mathrm{p}$} \\
\hline & Depressio & Depressio & & & ce & Depressio & Depressio & & \\
\hline & $\mathrm{n}$ & $\mathrm{n}$ & & & \multirow{2}{*}{ vs 2008} & $\mathrm{n}$ & $\mathrm{n}$ & & \\
\hline & $\mathrm{n}(\%)$ & $\mathrm{n}(\%)$ & & & & $\mathrm{n}(\%)$ & $\mathrm{n}(\%)$ & & \\
\hline \multirow{2}{*}{$\begin{array}{l}\text { Same or } \\
\text { increase }\end{array}$} & $392(77)$ & $191(81)$ & 1.5 & & Same & $348(59)$ & $154(60)$ & \multirow[t]{3}{*}{.11} & \\
\hline & & & 6 & 21 & & & & & 74 \\
\hline Decrease & $118(23)$ & 45 (19) & & & Increase & $240(41)$ & $101(40)$ & & \\
\hline \multirow{5}{*}{$\begin{array}{l}2011 \\
\text { Attendan } \\
\text { ce } \\
\text { vs } 2008\end{array}$} & Unelevate & Elevated & $\chi^{2}$ & $\mathrm{p}$ & 2011 & Unelevate & Elevated & \multirow[t]{5}{*}{$\chi^{2}$} & $\mathrm{p}$ \\
\hline & d BSI & BSI & & & Attendan & d BSI & BSI & & \\
\hline & Depressio & Depressio & & & ce & Depressio & Depressio & & \\
\hline & $\mathrm{n}$ & $\mathrm{n}$ & & & vs 2008 & $\mathrm{n}$ & $\mathrm{n}$ & & \\
\hline & $\mathrm{n}(\%)$ & n $(\%)$ & & & & $\mathrm{n}(\%)$ & $\mathrm{n}(\%)$ & & \\
\hline \multirow{2}{*}{$\begin{array}{l}\text { Same or } \\
\text { increase }\end{array}$} & $390(76)$ & $189(80)$ & 1.2 & . & Same & $315(54)$ & $142(56)$ & \multirow[t]{2}{*}{.32} & \\
\hline & & & 2 & 27 & & & & & 57 \\
\hline Decrease & $120(24)$ & $47(20)$ & & & Increase & $273(46)$ & $113(44)$ & & \\
\hline
\end{tabular}




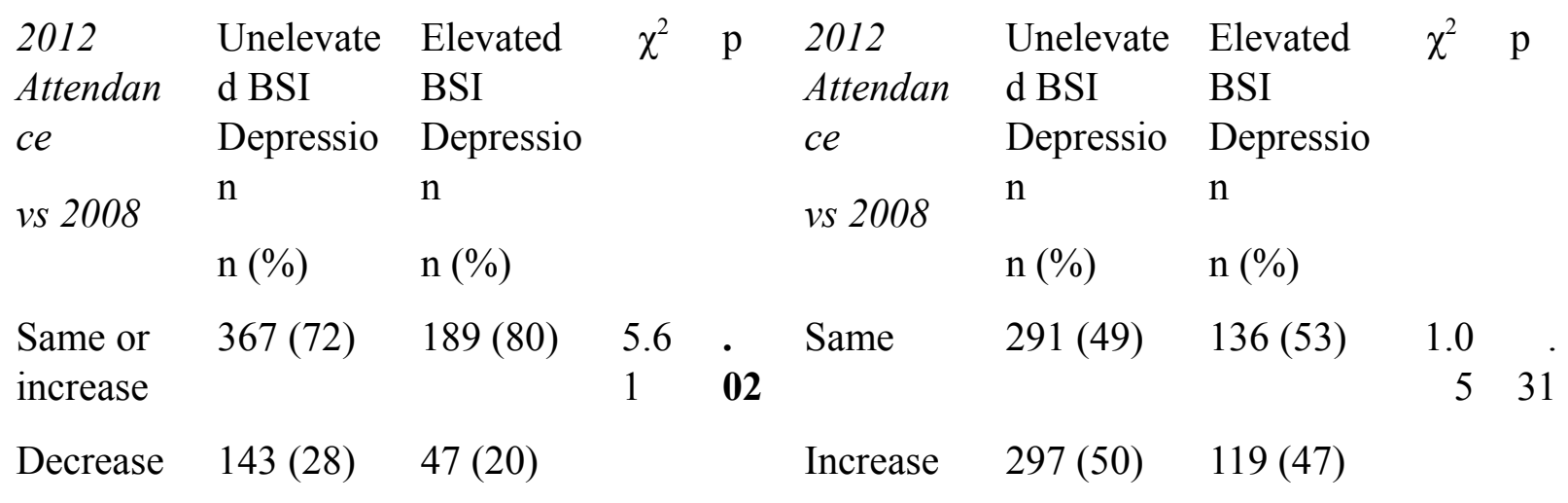

Note: If the individual had a norm-referenced score of "high" or "very high" in any of the three assessments in 2008, the individual was assigned to elevated and otherwise to unelevated. Abbreviation: BSI $=$ Brief Symptom Inventory 


\section{Table 3 (on next page)}

\section{Regression models}

In these models, the following covariates have been controlled: existing chronic condition, gender, marital status, income, and age. $p$ values: ${ }^{* * *}=.001,{ }^{* *}=.01,{ }^{*}=.05$ 
Table 3: Logistic Models of Change in Religious Attendance Levels over 5 years from the Longitudinal Internet Studies for the Social Sciences (LISS), Netherlands

\section{Religious Attenders at Baseline}

Model 1†:

Complete Cases

Relative Risk Ratio

(95\% CI)
Model 1A $\uparrow:$

Multiply imputed

data $(10$

imputations)

Relative Risk Ratio (95\% CI)

\section{Non-attenders at baseline}

Model 2†: $\quad$ Model 2A $\uparrow$ :

Complete Cases

Multiply imputed

data (10

imputations)

Odds ratio

(95\% CI)
Odds ratio

(95\% CI)

Outcome:

Decreased

Attendance

Predictor: Elevated

Depression

Outcome: Same

attendance

Outcome: Increased

attendance

Predictor: Elevated

Depression

\section{$0.55(0.38$ to}

$0.79) * *$

(Reference category)

$0.83)^{* * *}$
$0.58(0.41$ to

N/A

(Reference category)

$\dagger$ In these models, the following covariates have been controlled: existing chronic condition, gender, marital status, income, and age. $p$ values: ${ }^{\star \star \star}=.001,{ }^{\star *}=.01,{ }^{*}=.05$ 


\title{
Figure 2
}

\author{
probabilities
}

Predicted Probabilities of a Decrease, Same, and Increase in Religious Attendance $(95 \% \mathrm{Cl})$

Predicted Probabilities of a Decrease, Same, and Increase in Religious Attendance $(95 \% \mathrm{Cl})$
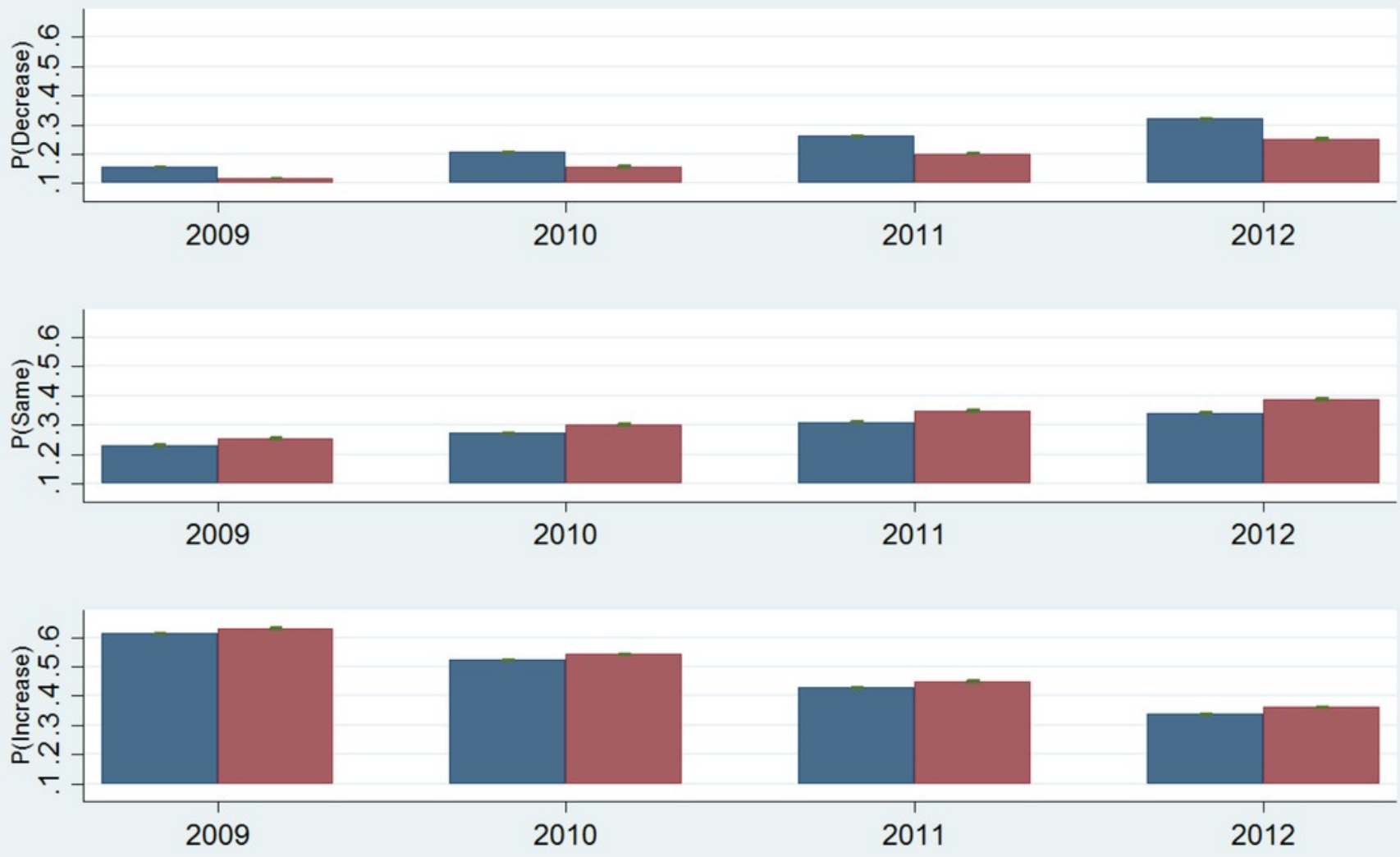

Unelevated Elevated

